\title{
IS IT POSSIBLE TO DETECT LUNG CANCER BY TRAINED DOGS?
}

\author{
Joanna Rudnicka ${ }^{1}$, Marta Walczak ${ }^{2}$, Tadeusz Jezierski ${ }^{2}$, Bogusław Buszewski ${ }^{1}$ \\ ${ }^{1}$ Department of Environmental Chemistry and Bioanalytics, Faculty of Chemistry, \\ Nicolaus Copernicus University \\ ${ }^{2}$ Institute of Genetics and Animal Breeding of Polish Academy of Sciences, Department of Animal Behaviour
}

Rudnicka J., Walczak M., Jezierski T., Buszewski B. (2015), Is it possible to detect lung cancer by trained dogs? Health Problems of Civilization, 2 (9), p. 19-26.

\begin{abstract}
Summary: During the illness are released volatile organic compounds with specific smell which could have in diagnosis of diseases. The firstaim of the study was qualitative and quantitative analysis of exhaled breath samples obtained from patients with lung cancer, healthy volunteers and people with other lung diseases by gas chromatography-mass spectrometry. This study showed that twenty compounds propane, ethanol, isobutane, butane, propanal, 1-propanol, 2-propanol, 2-methylfuran, 2-butanone, benzene, 2-pentanone, pentanal, hexanal, cyclohexanone, 4-heptanone, 2,4-dimethylheptane, 2,3,4-trimethylhexane, 2,3,5-trimethylhexane, 4-methyloctane, $\alpha$-pinene separated two research groups of patients and healthy controls.

The second goal was to evaluate the sensitivity and specificity of canine scent detection using 5 station scent lineup. Among lung cancer patients and complementary samples, overall sensitivity of canine scent detection was $85.54 \%$, while specificity was $71.84 \%$.
\end{abstract}

Keywords: breath samples, volatile organic compounds, solid phase microextraction, gas chromatography- mass spectrometry, canine olfactory

\section{Introduction}

Dogs (Canis familiaris) due to well-developed sense of smell were trained to detect drugs (Maejima et al. 2007; Lorenzo et al. 2003), explosives (Furton et al. 2001), identification of persons based on evidence scents (Schoon 1996), locating living people buried in debris or avalanches (Lit et al. 2006). Innovative and unconventional method is using of canine olfactory to detect different kind of cancer. The first reports about the possibility of detecting cancer in humans by a dog appeared in the Lancet in 1989, then in 2001 in both cases, dogs with no previous training have contributed to the detection of melanoma in their owners (Church et al. 2001; Williams et al., 1989). This fact has initiated research, the goal of which was to check whether training of dogs to detect different human cancer is possible. It have been applied in mentioned study different kind of odour source, e.g. melanoma tissue samples hidden on the skin of healthy volunteers (Pickel et al. 2004), urine samples for bladder, breast and prostate cancer detection (Gordon et al. 2008; Willis et al. 2004), tumour tissue for detecting ovary cancer (Horvath et al. 2008) and exhaled breath air for breast and lung detection (Ehmann et al. 2012; McCulloch et al. 2006; Walczak et al. 2012). The ability to explore odor stimuli depends on the size of the olfactory epithelium and olfactory cells. For example, German Shepherd has more than 200 million olfactory cells on the area of about $170 \mathrm{~cm}^{2}$, while the human has about 5 million cells on about $5 \mathrm{~cm}^{2}$ olfactory epithelium (Fig. 1). Olfactory receptors are stimulated only by gaseous substances floating in the air, which by diffusion gets in contact the mucous membrane and dissolve in the thin layer covering the mucous membrane. The ability to discriminate numerous compounds depends also on the proportion of genes of the olfactory receptor proteins (Browne et al. 2006; Rudnicka et al. 2014).

Address for correspondence: Bogusław Buszewski, Department of Environmental Chemistry and Bioanalytics, Faculty of Chemistry, Copernicus University, Gagarina 11, 87-100 Toruń, phone: +48 566114308, e-mail: bbusz@chem.uni.torun.pl

Tables: 0 Figures: 4 References: 24 Full-text PDF www.hpc.edu.pl Copyright (C) Pope John Paul II State School of Higher Education in Biała Podlaska, Sidorska 95/97, 21-500 Biała Podlaska Indexation: Index Copernicus, AGRO, ProQuest, Polish Medical Bibliography, Polish Ministry of Science and Higher Education. This is an open-access article distributed under the terms of the Creative Common Attribution Non-commercial license (http://creativecommons.org/licenses/by-nc/3.0), which permits use, distribution and reproduction in any medium, provided the original works is properly cited, the use is non-commercial and is otherwise in compliance with the license. 


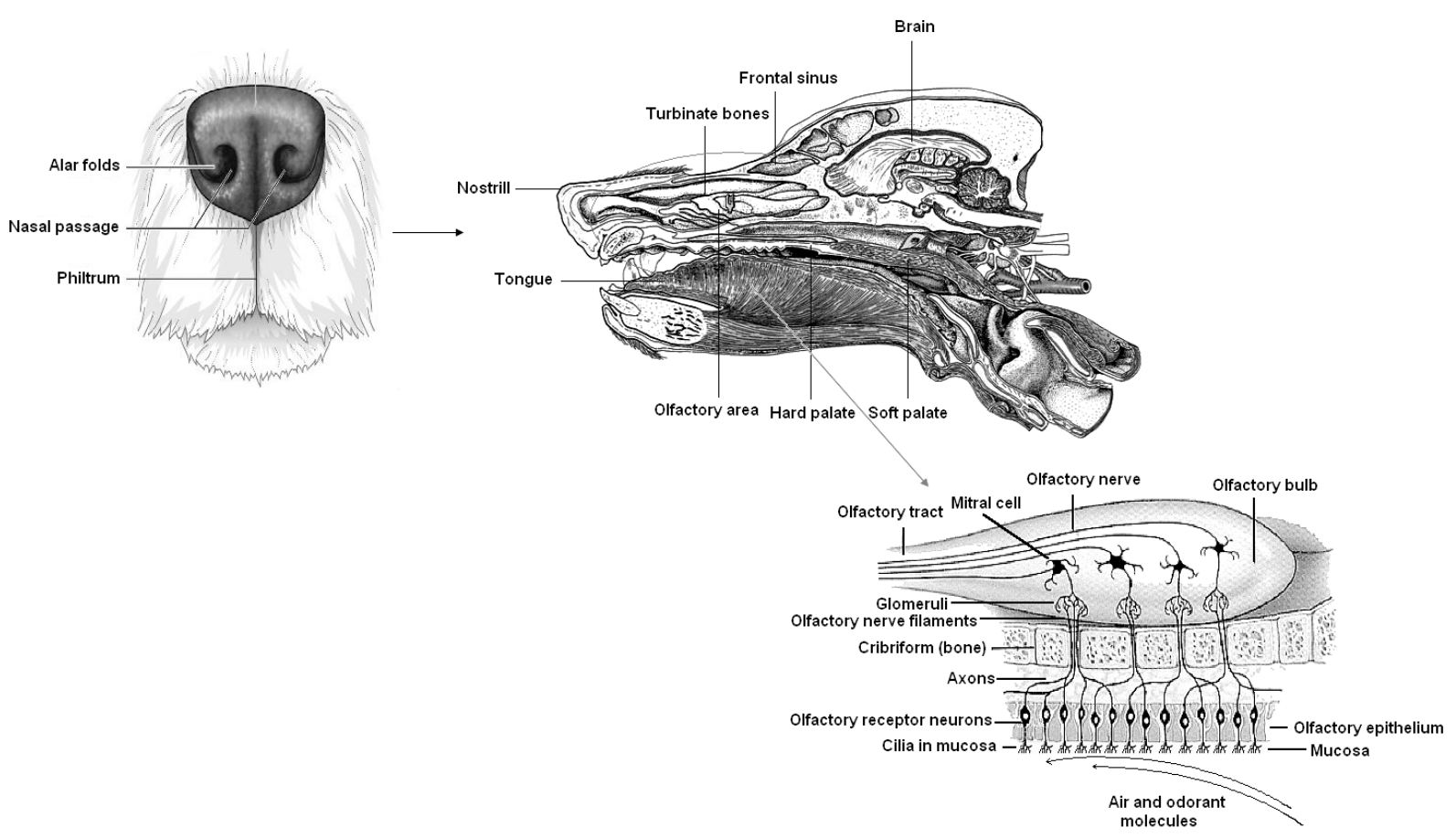

Figure 1. Canine sense of smell (Buszewski et al., 2012)

Odorant molecules, volatile organic compounds (VOCs) are typically small volatile organic molecules with molecular mass less than $400 \mathrm{Da}$ (Malnic et al. 1999). Some part of the compounds are generated in human body during metabolic process e.g. acetone which is formed by decarboxylation of acetoacetate and acetyl-CoA and which highest concentration could be a sign of diabetic disease. Isoprene is produced along the mevalonic pathway of cholesterol synthesis in the cytosolic fraction and it is identified as marker of disorders in cholesterol metabolism. Hydrocarbons, ethane and pentane are produced by lipid peroxidation of polyunsaturated fatty acids. Sulfur containing compounds like ethyl mercaptane, dimethylsulfide or dimethyldisulfide could be generated by incomplete metabolism of methionine in the transamination pathway. Whereas nitrogen containing compounds (dimethylamine, trimethylamine) are identified in breath patients with kidney impairment. Compounds such as acetone, hexanal and heptanal detected in blood and breath patients with lung cancer could be potential markers of cancer (Amann et al. 2004; Buszewski et al. 2007; Mazzone 2008). Biochemical origin, generation or physiological functions of most of VOCs are still not known.

Volatile organic compounds in human breath occur at the level parts per billion (ppb), therefore as the sampling technique solid phase microextraction (SPME) is mainly applied. After sampling of VOCs, identification of the components is performed most often by using gas chromatography-mass spectrometry (GC/MS) (Buszewski et al. 2007; Deng et al. 2004). Another techniques to detection of VOC in breath samples are selected ion flow tube-mass spectrometry (SIFT-MS), the reaction proton-transfer mass spectrometry (PTR-MS), electronic nose (Buszewski et al.2007).

\section{Experimental}

\subsection{Instrumentation}

The GC/MS analysis was performed on $6890 \mathrm{~N}$ gas chromatograph (Agilent Technologies, Waldbronn, Germany) coupled with spectrometer mass Agilent 5975 Inert XL MSD equipped with CP-Porabond-Q (Varian Inc., Middelburg, The Netherlands) $25 \mathrm{~m}$ x $0.25 \mathrm{~m} \mathrm{x} 3 \mu \mathrm{m}$ column. Oven temperature program was as follows: initial $40^{\circ} \mathrm{C}$ held for $2 \mathrm{~min}$, then ramped at $10^{\circ} \mathrm{C} / \mathrm{min}$ to $140^{\circ} \mathrm{C}$ and the ramped at $5^{\circ} \mathrm{C} / \mathrm{min}$ to $270^{\circ} \mathrm{C}$ and held for $5 \mathrm{~min}$. The temperature of the split-splitless injector was $200^{\circ} \mathrm{C}$. The MS analyses were carried out in full-scan mode, with scan mass range $\mathrm{m} / \mathrm{z} 30$ - 300. Spectra were collected at electron ionization (EI) $70 \mathrm{eV}$, both ion source and line transfer temperatures were set to $200{ }^{\circ} \mathrm{C}$. The acquisition of chromatographic data was performed by means of Chemstation software (Agilent). A manual SPME holder and carboxen/polydimethylsiloxane (CAR/ PDMS) $(75 \mu \mathrm{m}$ ) coated fiber (Supelco, Bellefonte, USA) were used for the SPME method (Rudnicka et al. 2014). 


\subsection{Calibration}

Prior to the use, the bulb was cleaned with methanol and dried in oven at $60{ }^{\circ} \mathrm{C}$ for at least $12 \mathrm{~h}$. Afterwards, it was purged with pure argon for $15 \mathrm{~min}$. Then, the bulb was evacuated by using vacuum pump within $30 \mathrm{~min}$. Gaseous standard were prepared by injection of 1-2 $\mu \mathrm{L}$ of each compound into $1 \mathrm{~L}$ glass bulb and its evaporation. Afterwards, the mixture was moved using gas syringe to $1 \mathrm{~L}$ Tedlar bag filled of $0.5 \mathrm{~L}$ of pure argon. Alkanes, alcohols, aldehydes and ketones were purchased from Sigma-Aldrich (Steinheim, Germany). Helium and argon, purity 99.999\%, were purchased from B.0.C. (Bydgoszcz, Poland) (Rudnicka et al. 2014).

\subsection{Solid Phase Microextraction}

Before the first use, the fiber was conditioned in an injector at $200{ }^{\circ} \mathrm{C}$ for $5 \mathrm{~h}$. During exposition, the SPME fiber was introduced into the bag containing sample of breath, through a silicone septum and was exposed for $10 \mathrm{~min}$, at $25^{\circ} \mathrm{C}$. After extraction, the fiber was withdrawn to the needle, pulled out from the bag and injected into the GC. The compounds were desorbed in the hot GC injector port for 2 min at $200{ }^{\circ} \mathrm{C}$ (Rudnicka et al. 2014).

\subsection{Participants and breath samples collection}

\subsubsection{Basic data for participants researches}

Exhaled breath samples were collected from 108 patients with lung cancer confirmed by histopathological examination, recruited from Department of Lung Diseases, Collegium Medicum, Nicolaus Copernicus University, Torun, Poland. These included 74 patients with non-small cell lung cancer (I stage of cancer was 5, II- 12, III-22, IV-35), 15 patients with small cell lung cancer collected (stage of cancer- ED) and 19 patients with not specified histological type. Breath samples were collected from 24 patients with other lung disease (asthma, COPD or pneumonia) and 121 self-declared healthy volunteers.

For each participant the questionnaire was filled out. In order to follow ethical requirements, all breath sample donors were informed about aim of the study. The experimental procedure was approved by the Ethical Commission (Nicolaus Copernicus University in Torun, Ludwik Rydygier Collegium Medicum, Bydgoszcz).

\subsubsection{Breath sample collection for GC/MS analysis}

Breath samples were collected into a $1 \mathrm{~L}$ Tedlar bags using breath sampler (Medical University of Innsbruck, Austria). The device allowed to collect alveolar exhaled air samples. Before collection of breath, all bags were cleaned by flushing with argon gas and then filled with argon and heated at $60^{\circ} \mathrm{C}$ for $12 \mathrm{~h}$ to remove any contaminations. Afterwards, a $200 \mathrm{ml}$ sample with bags was transferred into second bag. Sample of breath were analyzed within 3-4 hours to prevent loss volatile organic compounds with bag. Ambient air samples were taken for measurement blank (Rudnicka et al. 2014).

\subsubsection{Collection of breath samples for testing by dogs}

Cylindrical polypropylene tubes $14 \mathrm{~cm}$ long, outer diameter $3 \mathrm{~cm}$ (Defencetek, Pretoria, South Africa) with removable inserts filled with oil-coated polypropylene absorbent were used for collecting of exhaled breath. Breath samples were collected by performing 3 deep exhalations into sampling tubes. Subsequently, the tubes were fitted with their end caps and wrapped into sterile plastic bags and store in room temperature between the time of breath sampling and presentation to the dogs. For the test removable inserts were taken out of the tubes and put in sterile glass vessel covered with hole-punched lids to prevent the dog's nose from touching the insert with breath sample during sniffing (Rudnicka et al. 2014).

\subsection{Canine detection procedure}

The tests using sniffing dogs were carried out at the Department of Animal Behavior, Institute of Genetics and Animal Breeding, Polish Academy of Sciences, Jastrzebiec, Poland.

Two male dogs (German shepherds mixed) were used in this study. Earlier the dogs have completed a special training using operant conditioning (a reward based training method) in 5 station scent lineup to distinguish between breath samples collected form melanoma, lung and breast cancer patients from those of healthy donors. The details of the canine training were given elsewhere (Walczak et al., 2012).

The tests were conducted in a laboratory condition, in room isolated from external stimuli. During the tests only the experimenter and the dog handler were present in the laboratory room. Five pots, heavy enough to 
prevent pushing by dogs during sniffing, were placed on the floor in a lineup approximately $1 \mathrm{~m}$ apart. The propylene boxes with breath samples were put into pots by the experimenter. One target sample containing breath sample from cancer patient was placed in a randomly selected position in the lineup and the remaining four pots contained complementary samples from healthy donors, donors with other lung diseases or synthetic samples. Than the dog handler, who was never aware of the position of target sample, encouraged the dog to sniff all pots in the lineup. If the dog sat down in front of the cancer sample the experimenter gave an acoustic signal using a clicker device for a correct response of the dog and the dog handler immediately rewarded the dog with verbal praise and a piece of food. The experimenter was invisible to the dog and observed the trials through video monitor. Daily each dog performed approximately 10 trials (walking along the scent lineup and sniffing the samples). The experimental procedure and keeping conditions for dogs were approved by the $3^{\text {rd }}$ Local Ethical Commission for Animal Experimentation in Warsaw, Poland (Rudnicka et al. 2014).

\section{Results and discussion}

\subsection{Data analysis of measurements SPME-GC/MS}

\subsubsection{Validation of the method}

The precision of the method was determined by performing three analyses. The value of the relative standard deviation (RSD) was in the range from $3.36 \%$ to $9.54 \%$ for hydrocarbons, alcohols, aldehydes, ketones and aromatic compounds. RSD values less than $10 \%$ show that the present method has good repeatability. A calibration curve was linear for aliphatic hydrocarbons in the range 3.16-106.05 ppb, for alcohols 3.91-418.66 ppb, for aldehydes 5.09-217.82 ppb, for ketones 3.77-332.93 ppb, for aromatic compounds 4.96-165.61 ppb, esters 6.26-153.78 ppb, compounds containing sulfur 8.32-203.23 ppb, acetonitrile 11.7-234.03 ppb, ethyl ether 5.88-117.64 ppb and terpenes $3.77-75.46 \mathrm{ppb}$. The linear correlation coefficients were higher than 0.9914. The lowest values of LOD were obtained for hydrocarbons and aromatic compounds in the range of 1.34-4.90 ppb and 2.50-5.07 ppb, respectively (Rudnicka et al. 2014).

\subsubsection{Breath analysis}

In the section was presented identified compounds in breath sample without regard ambient air, because exhaled air samples were prepared to test with dogs included ambient air.

In human breath from patients with lung cancer, asthma and COPD and healthy were detected 89 compounds which belong to the classes compounds such as ketones, aldehydes, furans, alcohols, nitryles, esters, aromatic hydrocarbons, sulfur compounds, hydrocarbons saturated and unsaturated. In exhaled air by patients with lung cancer content of alcohols in comparison with healthy volunteer and persons with another diseases lung is the higher (9.14 \%), whereas the amount aldehydes (12.83\% - 14.99\%) and ketones (12.64 \% - $12.69 \%)$ is greater for persons with asthma, COPD and lung cancer. The content compounds belong to the class hydrocarbons saturated and aromatic hydrocarbons in all three research group is similar, in the range $25 \%$ - $27 \%, 9.17 \%$ $9.64 \%$, respectively (Figure 1 a-c).

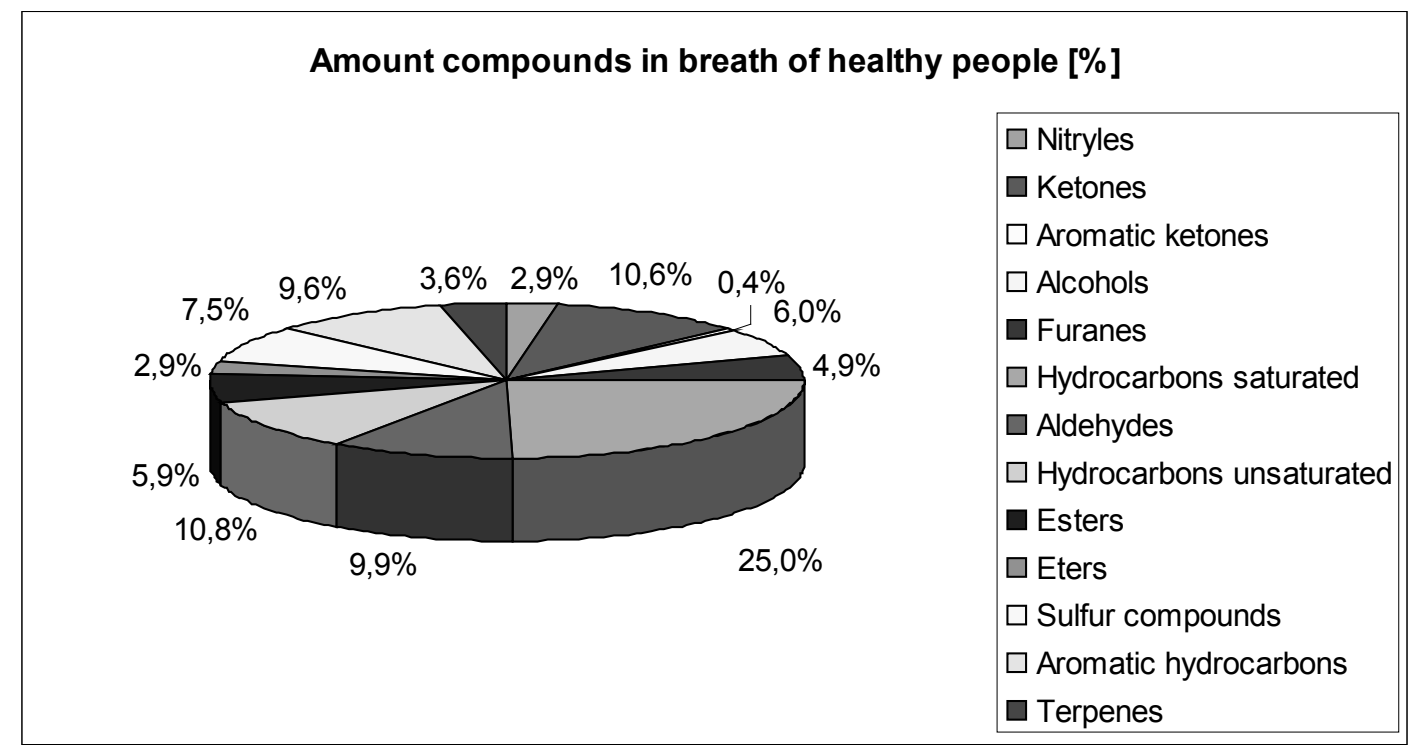



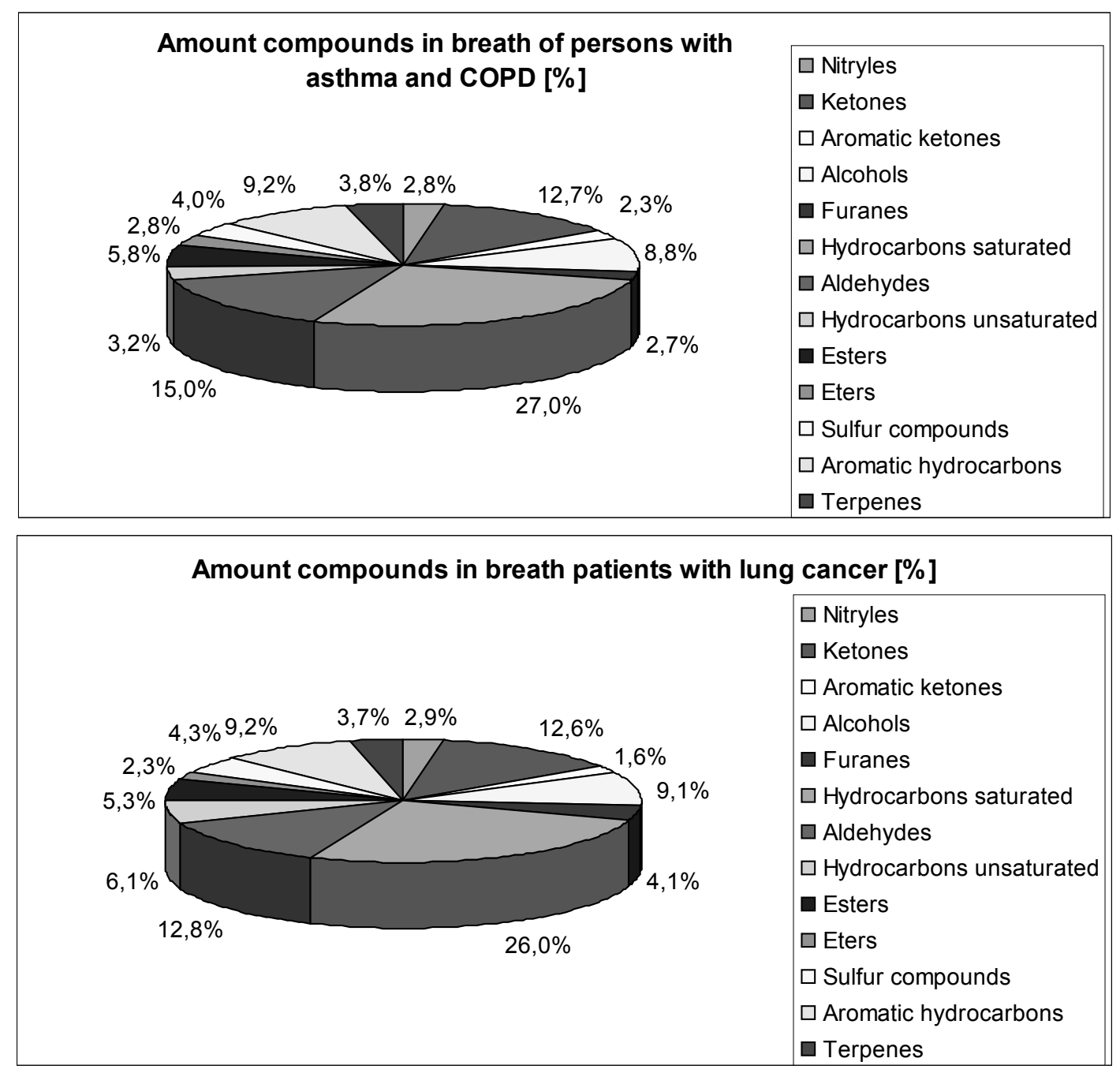

Figure 2. Amount of particular class compounds in human breath a) healthy persons b) patients with asthma and COPD c) lung cancer patients

Compounds such as acetone and isoprene were detected in all samples. In exhaled air of patients with lung cancer in comparison to breath healthy person wereidentified compounds such as propane, acetaldehyde, ethanol, isobutene, butane, 2- propenal, propanal, carbon disulfide, 2-propanol, 1-propanol, 2-methylbutane, 3-methyl1-butyn, metacroleina, methylvinyl ketone, 2,3-butanedione, 2-methylfuran, 2-butanone, 3-methylfuran, 2-methylo-1-propanal, 2,3-dimethylpentane, 2-methylopentane, benzene, cyclohexene, 2-pentanone, pentanal, 1-pentanol, hexanal, 3-methyl-2-pentanone, 2-methyloheptane, cyclohexanon, 4-heptanone, benzaldehyde, heptanal, 2,4-dimethylheptane, 2,3,4-trimethylhexane, 2,3,5-trimethylhexane, 4-methyloctane, 3-carene, $\alpha$-pinene, octanal, limonene, dodecane.

The level of concentration acetone, isoprene, ethanol, 1-propanol, 2-propanol, hexanal, dimethyl sulfide were higher in patients with lung cancer than in case of healthy volunteers and persons with other lung diseases. Furan and dimethyl sulfide were not detected in patients with asthma and COPD, whereas 4-heptanone was not identified healthy volunteers. Presence in exhaled air compounds such as alkanes, ketones, aldehydes are produced in human body as product of metabolic processes. Acetone is formed in decarboxylation of acetoacetate and acetyl-CoA, pentane is produced during lipid peroxidation, however other part have origin exogenous (Buszewski et al., 2007).

\subsection{Results of experiment with the dogs}

Figure 2 shows overall percentage of indications for particular type of samples. Dogs correctly detected $85.54 \%$ of sniffed samples from patients with lung cancer. 
Samples from patients with lung cancer were differentiated significantly better $(\mathrm{p}<0.001)$ than samples obtained from patients with other lung diseases (42.17\%). Percent of true positive indications of cancer samples was also significantly $(\mathrm{p}<0.001)$ higher than percent of false positive indications of samples from healthy volunteers $(28.16 \%)$.

False positive rate of samples from patients with lung diseases without cancer confirmation was significantly $(\mathrm{p}<0.001)$ higher than false positive rate of samples from healthy volunteers.

The dogs indicated $20.93 \%$ of sniffed synthetic samples prepared on the basis of exhaled air of cancer patients and $16.21 \%$ of samples prepared on the basis of exhaled air of the healthy volunteers. This results was significantly $(\mathrm{p}<0.001)$ lower than percentage of indications of cancer samples or rate of indication of samples from patients with other lung diseases.

In detection of particular type of samples used the significant differences were observed between the dogs (Figure 3).

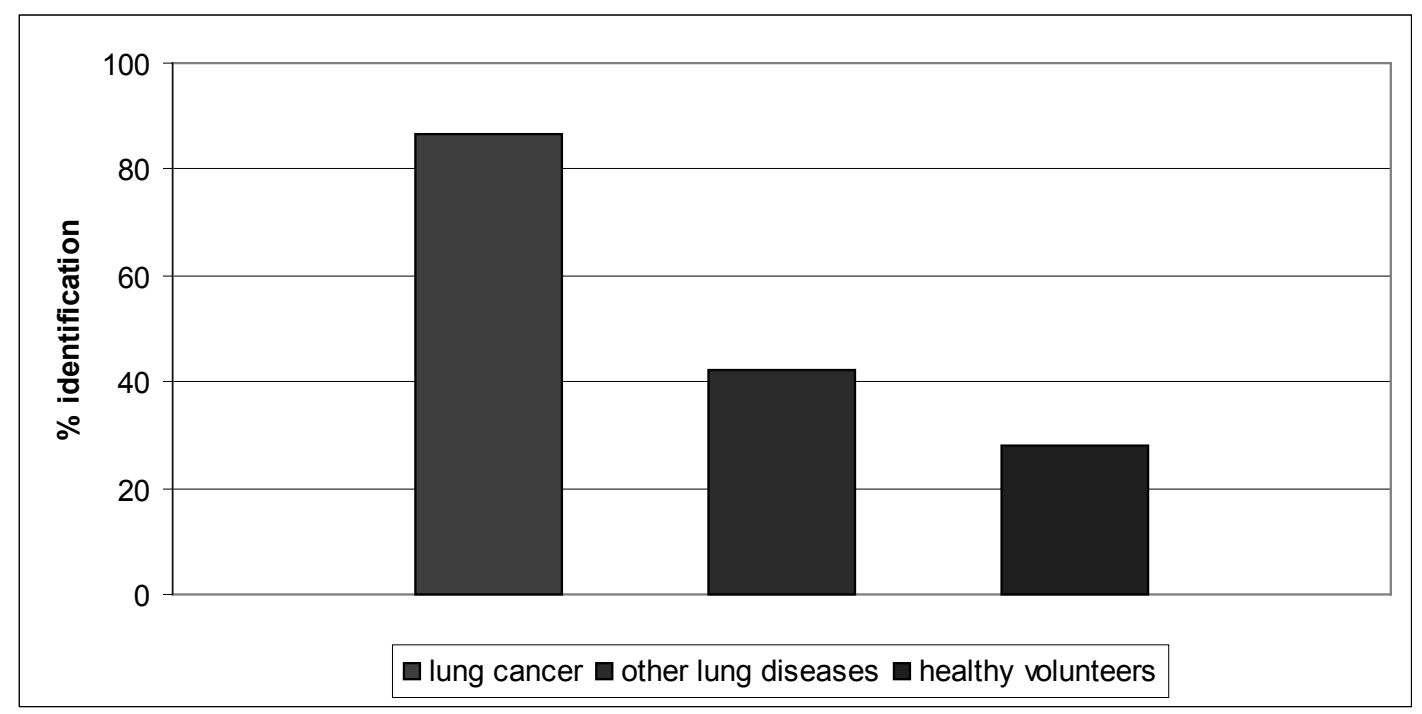

Figure 3. Overall percentage of indications for particular type of samples

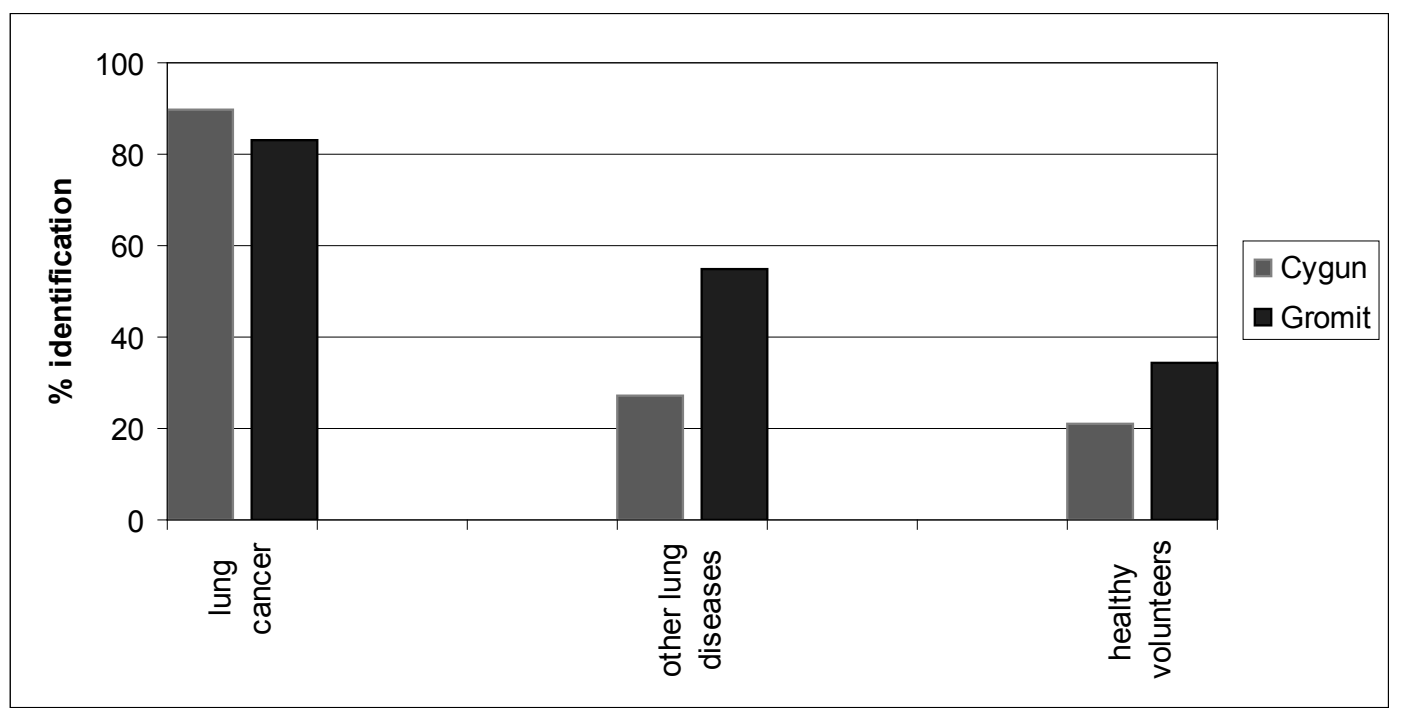

Figure 4. Percentage of indications for particular type of samples for two dogs

The ROC curve (ROC), a plot of sensitivity vs 1- specificity is typically used to evaluate clinical utility for both diagnostic and prognostic models. In a ideal test, with no false positive or false-negative results, the curve forms a right angle in the upper left corner of the chart and area under the curve equal 1.0. If accuracy of the test deteriorates, the curve becomes rounded. Area under the curve ROC (AUC) shows the ability of a test or detection method for distinguishing true and false results, is a measure of the quality of the method in this way 
if AUC 0.5 means no predictive ability and AUC 1 means perfect discrimination (Zou et. al, 2007). The relative area under the ROC curve in the case of lung cancer was ranged from $78 \%$ to $90 \%$. In figure 4 it was shown an example of ROC curve for detection of lung cancer by dogs. The two parameters of detection were calculated based on the following formulas:

where:

$$
\begin{aligned}
& \text { sensitivity }=\mathrm{CP} /(\mathrm{CP}+\mathrm{MI}) \\
& \text { specificity }=\mathrm{CN} /(\mathrm{CN}+\mathrm{FA})
\end{aligned}
$$

1. Correct positive indications (CP), when a dog indicated the target sample

2. Correct negative response $(\mathrm{CN})$, when a dog refrained from indicating a control sample

3. False positive alert (FA), an indication of a blank or control sample

4. False negative response (a miss, MI), not indicating the pattern sample

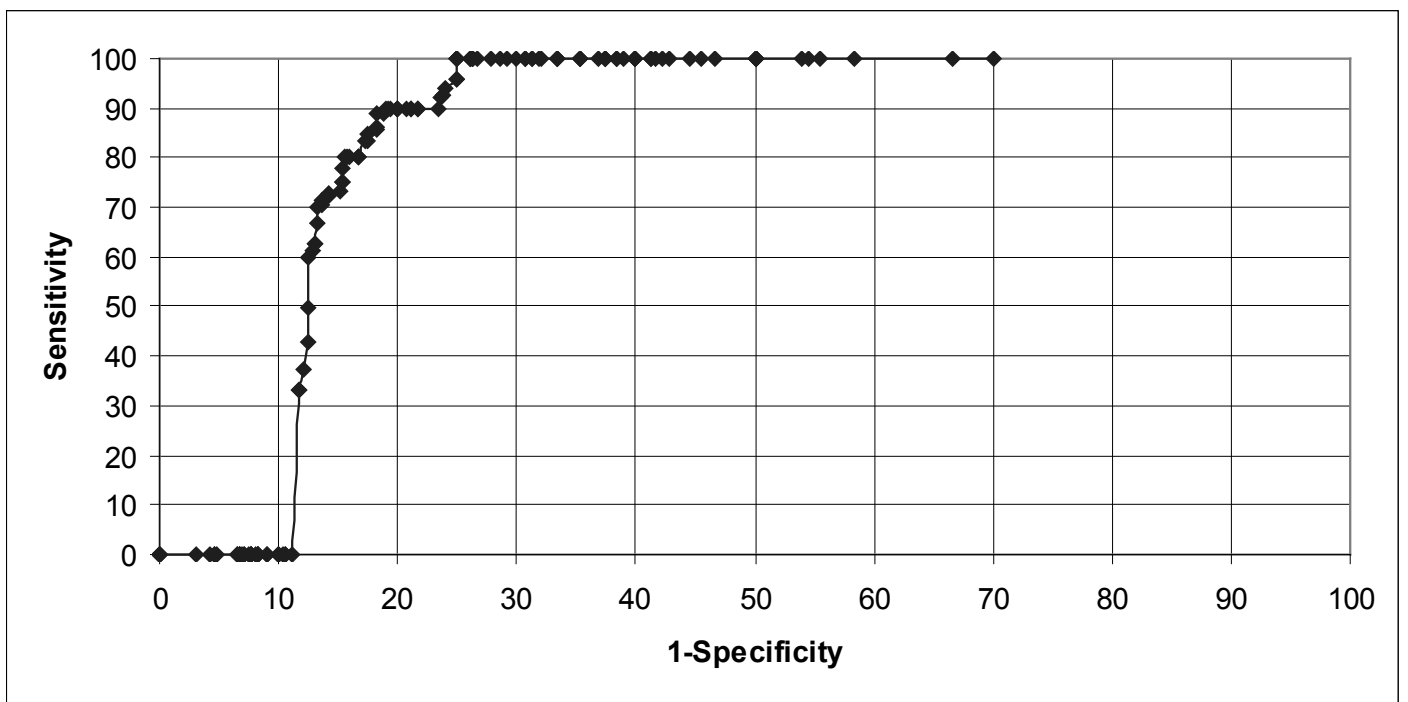

Figure 5. Receiver operating characteristic curve (ROC) for breath samples collected from patients with lung cancer

\section{Conclusions}

A combination the solid phase microextraction and gas chromatography-mass spectrometry (SPME-GC/MS) and sniffer dogs application to detection compounds in human breath samples were discussed. The technique was applied to determination composition breath the 108 patients with lung cancer, 24 asthma/COPD and 121 volunteers. The total number of compounds identified in sample of breath equal 123 by GC/MS. The sensitivity detection sample of lung cancer by trained dogs equal $86 \%$, whereas specificity $72 \%$.

Presented an analytical and canine methods for detection composition of exhaled air could be applied as a potential non-invasive tool for screening of lung cancer.

\section{Acknowledgement}

This paper was supported from the budget of Kuyavia and Pomerania and the European Regional Development Fund under the ROP for the years 2007 - 2013: project no. RPKP.05.04.00-04-003/13.

\section{References:}

1. Amann A., Poupart G., Telser S., Ledochowski M., Schmid A., Mechtcheriakov S. (2004), Applications of breath gas analysis in breath. Int. J. Mass Spectrom.; 239: 227 - 233.

2. Browne C., Stafford K., Fordham R. (2006), The use of scent-detection dogs. Irish Vet. J.; 2: 97-104.

3. Buszewski B., Kęsy M., Ligor T., Amann A. (2007), Human exhaled air analytics: biomarker. Biomed. Chromatogr.; 21: 553 - 566. 
4. Buszewski B, Rudnicka J., Ligor T., Walczak M., Jezierski T., Amann A. (2012), Analytical and unconventional methods of cancer detection on the base of odor. TrAC; 38: 1-12.

5. Church J., Williams H. (2001), Another sniffer dog for the clinic? The Lancet; 358: 930.

6. Deng C., Zhang J., Xiaofeng Y., Zhang W., Zhang X. (2004), Determination of acetone in human breath by gas chromatography-mass spectrometry and solid-phase microextraction with on-fiber Derivatization. J. Chromatogr. B; 810: 269-275.

7. Ehmann R., Boedeker E., Friedrich U., Sagert J., Dippon J., Friedel G., Walles T. (2012), Canine scent detection in the diagnosis of lung cancer: Revising a puzzling phenomenon. European Respiratory Journal; 39: 669-676.

8. Furton K.G., Myers L.J. (2001), The scientific foundation and efficacy of the use canines as chemical detectors for explosives. Talanta; 54: 487-500.

9. Gordon R., Beck Schatz C., Myers L.J., Kosty M., Gonczy C., Kroener J., Tran M., Kurtzhaks P., Heath S., Koziol J.A., Arthur N., Gabriel M., Hemping G., Nesbitt S., Trucker-Clark L., Zaayer J. (2008), The use of canines in the detection of human cancers. J. Altern. Complemen. Med.; 14: 61-67.

10. Horvath G., Järverud G.K., Järverud S., Horváth I. (2008), Human ovarian carcinomas detected by specific odor. Integr. Cancer Ther; 7 (2): 76-80.

11. Lorenzo N., Wan T.L., Harper R.J., Hsu Y.-L., Chow M., Rose S., Furton K.G. (2003), Laboratory and field experiments used to identify Canis lupus var. familiaris active odor signature chemicals from drugs, explosives, and humans. Anal. Bioanal. Chem.; 376: 1212-1224.

12. Lit l., Crawford C.A. (2006), Effects of training paradigms on search dog performance. Appl. Anim. Behav. Sci.; 98: 277-292.

13. Maejima M., Inoue- Murayama M., Tonosaki K., Matsuura N, Kato S., Saito Y., Weiss A., Murayama Y., Ito S. (2007), Traits and genotypes may predict the successful training of drug detection dogs. Appl. Anim. Behav. Sci.; 107: 287-298.

14. Malnic B., Hirono J., Sato T., Buck L.B. (1999), Combinatorial receptor codes for odors. Cell; 96: 713-723.

15. Mazzone P.J. (2008), Analysis of volatile organic compounds in the exhaled breath for the diagnosis of lung cancer. J. Thorac. Oncol.; 3: 774-780.

16. McCulloch M., Jezierski T., Broffman M., Hubbard A., Turner K., Janecki T. (2006), Diagnostic accuracy of canine scent detection in - early and laste - stage and breast cancers. Integr. Cancer Ther.; 5: 1-9.

17. Pickel D., Manucy G. P., Walker D.B., Hall S. B., Walker J.C. (2004), Evidence for canine olfactory detection of melanoma. Appl. Anim. Behav. Sci.; 89: 107-116.

18. Rudnicka J., Walczak M., Kowalkowski T., Jezierski T., Buszewski B. (2014), Determination of volatile organic compounds as potential markers of lung cancer by gas chromatography - mass spectrometry versus trained dogs. Sensors and Actuators B: Chemical; 202: 615-621.

19. Schoon G.A.A. (1996), Scent identification lineups by dogs (Canis faliliaris): experimental design and forensic application. Appl. Anim. Behav. Sci.; 49: 257-267.

20. Walczak M., Jezierski T., Górecka-Bruzda A., Sobczyńska M., Ensminger J. (2012), Impact of individual training parameters and manner of taking breath odor samples on the reliability of canines as cancer screeners. J. Vet. Behav.; 7: 283-294.

21. Westmoreland D.G., Rhodes G.R. (1989), Analytical techniques for trace organic compounds-II. Detectors for gas chromatography. Pure\&Appl. Chem.; 61: 1147-1160.

22. Williams H., Pembroke A.( 1989), Sniffer dogs in the melanoma clinic? The Lancet; 1, 734.

23. Willis C. M., Church S.M., Guest C.M., Cook A.W., McCarthy N., Bransbury A.J., Church M. R. T., Church J. C. T. (2004), Olfactory detection of human bladder cancer by dogs: proof of principle study. Br. Med. J., 329: $712-715$.

24. Zou K.H., O’Malley A.J., Mauri L. (2007), Receiver-operating characteristic analysis for evaluating diagnostic tests and predictive models. Circulation; 115: 654-657. 